\title{
CARDIAC AMYLOIDOSIS IN A PATIENT WITH MULTIPLE MYELOMA
}

Parathan K. K ${ }^{1}$, Mahendra Kumar K², Kannan R ${ }^{3}$, Chitrambalam P4, Volga $\mathrm{H}^{5}$

\section{HOW TO CITE THIS ARTICLE:}

Parathan K. K, Mahendra Kumar K, Kannan R, Chitrambalam P, Volga H. "Cardiac Amyloidosis in a Patient with Multiple Myeloma". Journal of Evolution of Medical and Dental Sciences 2015; Vol. 4, Issue 81, October 08;

Page: 14248-14252, DOI: 10.14260/jemds/2015/2026

ABSTRACT: Cardiac amyloidosis is a rare disorder, which is characterised by the extra cellular deposition of amyloid, a protein polysaccharide complex in the heart. This infiltrative cardiomyopathy presents with restrictive heart failure. We report a 58 year old male who presented with macroglossia, proteinuria and heart failure. His detailed evaluation revealed multiple myeloma with concurrent Primary (AL) amyloidosis. This case report is to highlight the occurrence of cardiac amyloidosis and multiple myeloma which are two separate plasma cell dyscrasias which have presented together.

KEYWORDS: Cardiac amyloidosis, Multiple myeloma, AL Amyloidosis, Macroglossia.

CASE PRESENTATION: A 58 year old male presented with a 10 month history of slowly progressive abdominal distension, swelling of both legs, shortness of breath and orthopnea. He also complained of generalized fatigue, loss of weight and appetite. On general examination, he had an elevated jugular venous pressure, pallor, normal blood pressure, macroglossia (Fig.1) and pitting edema of both lower limbs up-to the level of the knees.

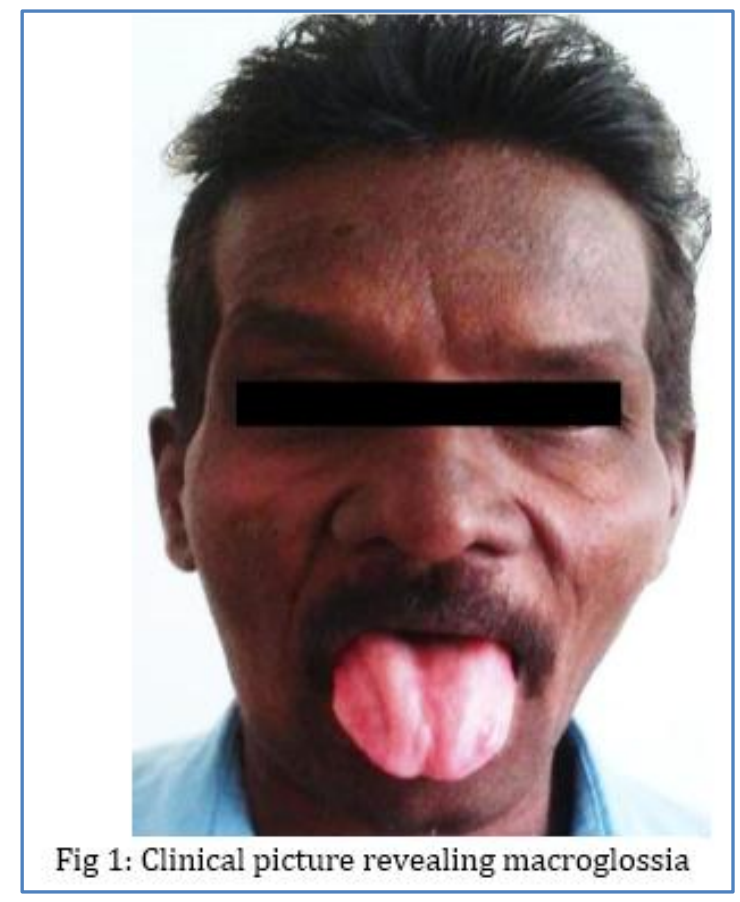

Systemic examination revealed a soft grade 2/6 systolic murmur in the pulmonary area, hepatomegaly and ascites. Investigations revealed a normocytic anemia (Haemoglobin: $8.4 \mathrm{mg} / \mathrm{dL}$, Red blood cells: 3.17x106/cu.mm and Mean Corpuscular Volume: $86 \mathrm{fl}$ ) and elevated ESR (130mm at 1 


\section{CASE REPORT}

hour). The serum albumin level was $2.7 \mathrm{~g} / \mathrm{dL}$ and globulin level was $7.4 \mathrm{~g} / \mathrm{dL}$. His renal parameters were normal and urinalysis revealed proteinuria (1280mg per day). Liver function tests revealed elevated alkaline phosphatase of $204 \mathrm{U} / \mathrm{L}$ (Normal range: 26-120U/L). Serum protein electrophoresis revealed an M spike (Fig.2) and immunofixation electrophoresis was positive for IgG $\lambda$ (Fig 3).

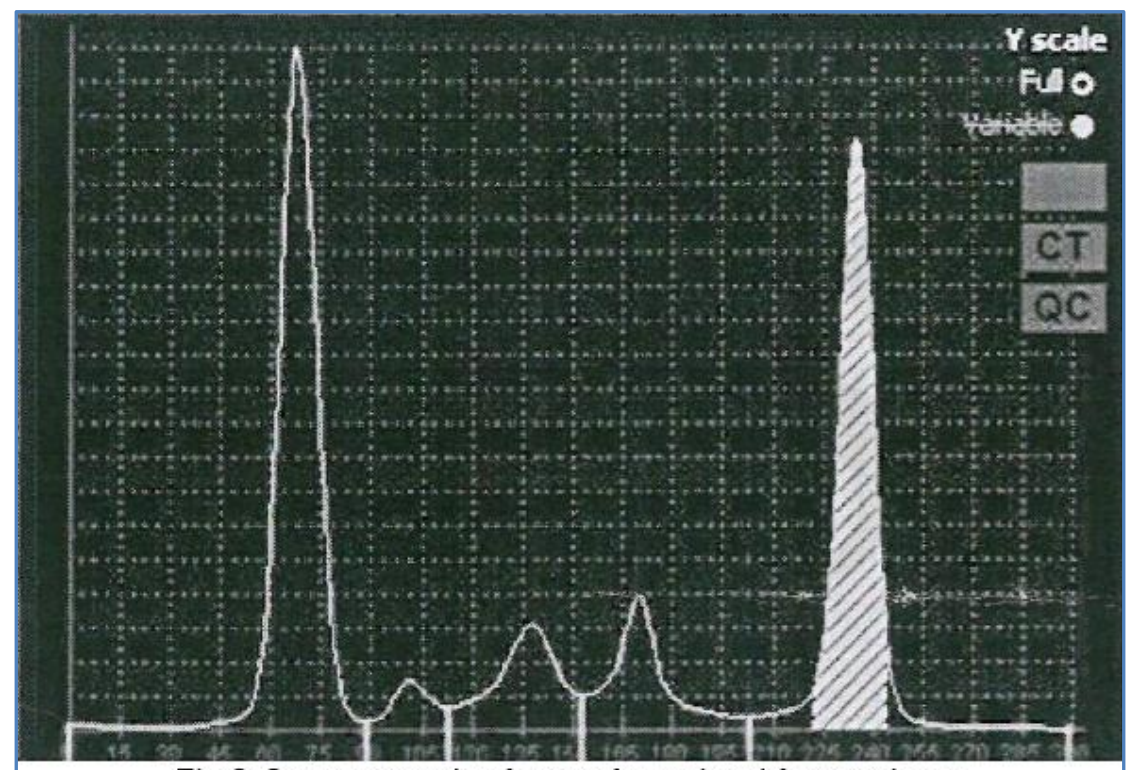

Fig 2. Serum protein electrophoresis with prominent $\mathrm{M}$ spike in the gamma region

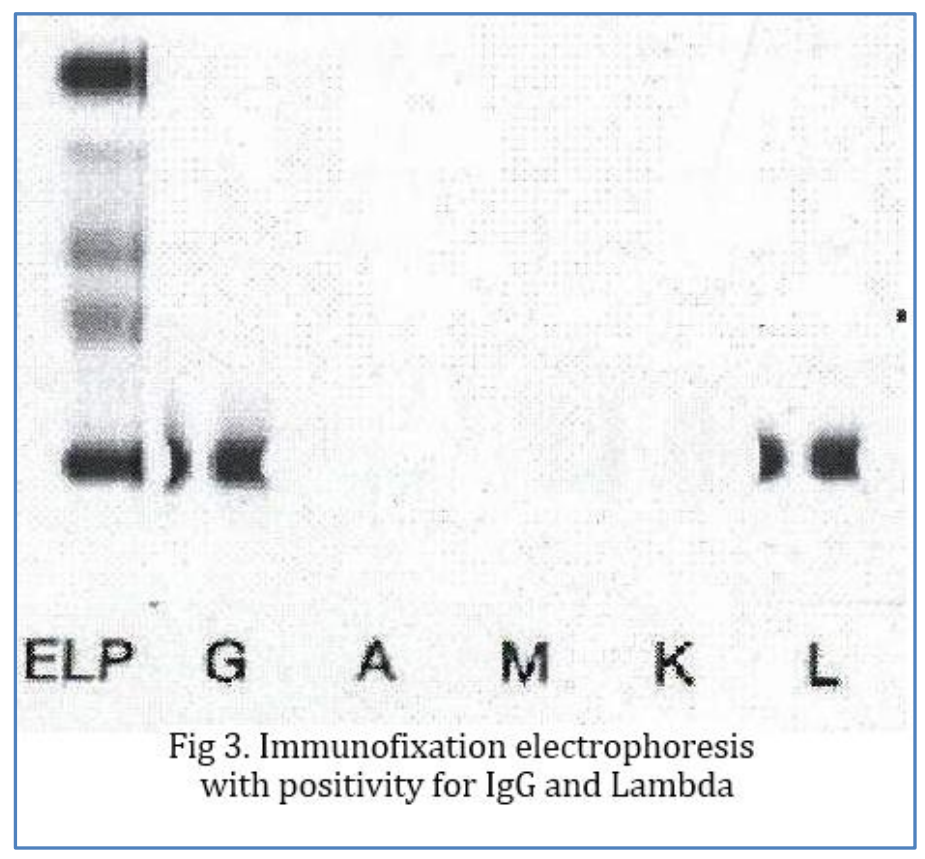

Thyroid function tests were normal. The electrocardiogram revealed a $1^{\text {st }}$ degree AV block. Abdominal Ultrasound revealed hepatomegaly with ascites. Echocardiography showed biatrial enlargement with biventricular hypertrophy and a hyperechoic, granular myocardium which was 


\section{CASE REPORT}

suggestive of amyloid infiltration. Radiological investigations revealed cardiomegaly with right sided pleural effusion, punched out lesions were detected in skull and diffuse osteopenia of the spine. (Fig $4 a, 4 b)$.

Fig. 4a: CT imaging of skull showing well defined punched out lytic lesions in skull bones

Fig. 4b: Sagittal CT sections of lumbar spine showing thickened marrow trabeculations with illdefined lytic areas in vertebral bodies of lumbar spine.

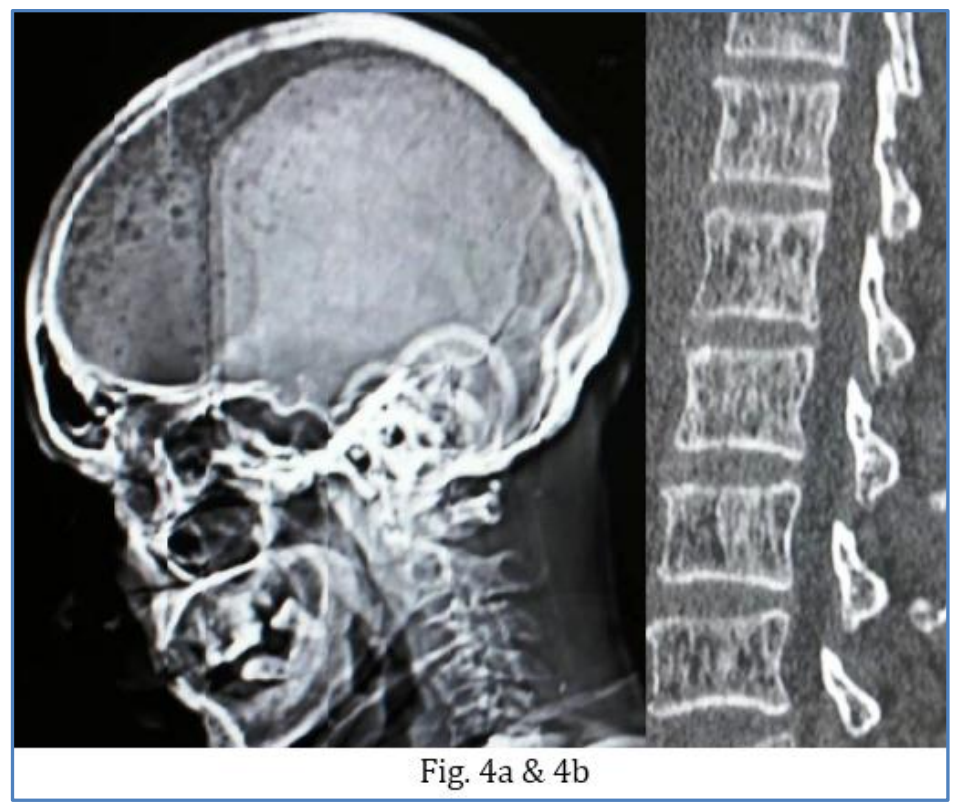

Peripheral smear study showed typical rouleax formation. Bone marrow examination revealed plasma cells with cart wheel chromatin suggestive of multiple myeloma. (Fig 5)

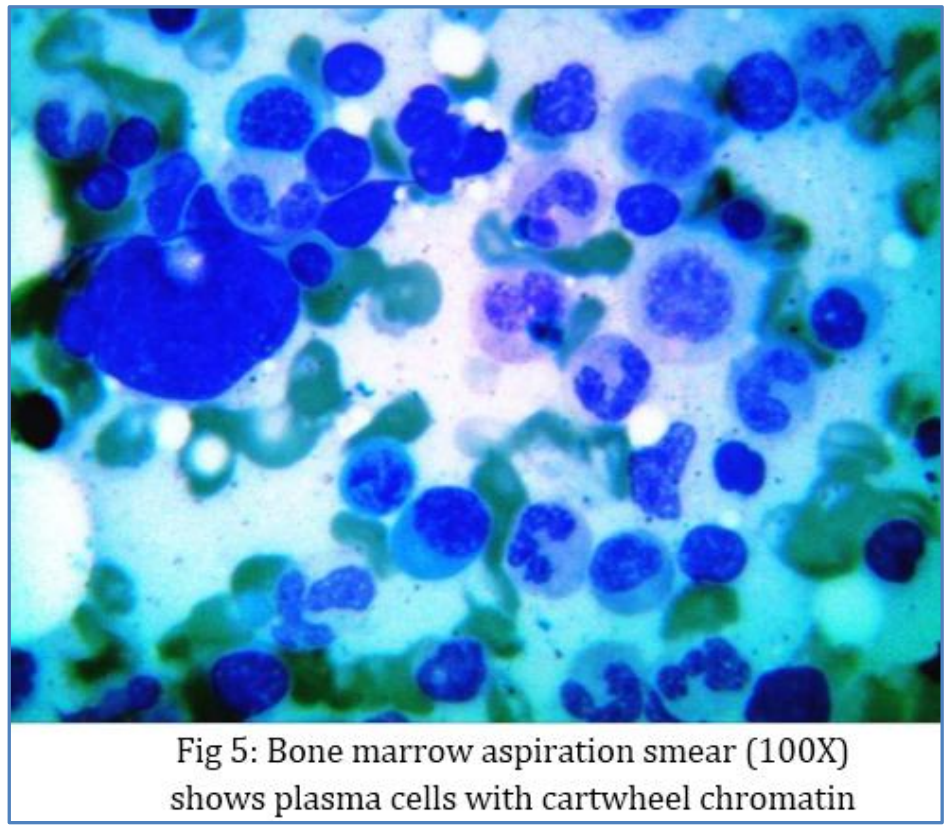


He received treatment for heart failure with furosemide and spironolactone and his condition improved. He was started on cyclophosphamide, thalidomide and dexamethasone and is under our follow-up.

DISCUSSION: Multiple myeloma (MM) is a common haematological malignancy characterised by the proliferation of abnormal clonal terminally differentiated plasma cells. ${ }^{1}$ Routine use of comprehensive laboratory panels has helped to diagnose MM in many asymptomatic patients, who constitute up to $1 / 3^{\text {rd }}$ of all patients. ${ }^{2}$

Our patient fulfilled all 3 diagnostic criteria (Values in parentheses) for multiple myeloma. ${ }^{3}$ Hepatomegaly is more commonly associated with it than splenomegaly and about $10 \%$ of the patients will exhibit macroglossia. ${ }^{4}$ Infrequently, it manifests as a local disorder, restricted to a single organ $^{2}$. Macroglossia with indented tongue is considered pathognomonic of AL amyloidosis.

Cardiac involvement, in the form of restrictive cardiomyopathy is present in up to $50 \%$ of patients with AL amyloidosis. The presence of ventricular hypertrophy in the absence of systemic hypertension along with the presence of granular \& hyperechoic myocardium in our case leads to the suspicion of cardiac amyloidosis 5 .

The 24 hour urinary protein of $1280 \mathrm{mg}$ /day denotes the renal involvement in amyloidosis. The definite diagnosis of AL amyloidosis requires histopathological confirmation but the patient refused biopsy. But the presence of involvement of multiple organs, in a characteristic manner, helps us make a diagnosis of AL amyloidosis with reasonable certainty.

Multiple myeloma and AL amyloidosis are both clonal plasma cell proliferative disorder which present with different phenotypes. Among the two, multiple myeloma is more common, with a 10 fold higher prevalence. ${ }^{6}$ The progression of AL amyloidosis to multiple myeloma is very rare but a diagnosis of $\mathrm{AL}$ amyloidosis is made frequently in patients with pre-existing multiple myeloma.7 This represents the coexistence of two separate but overlapping diseases of the plasma cell and shouldn't be wrongly labelled as multiple myeloma with secondary amyloidosis. ${ }^{8}$

Our patient has features of cardiac amyloidosis and macroglossia which favour a diagnosis of AL amyloidosis. Even though the percentage of plasmacytes in the marrow is less than $30 \%$, the presence of lytic lesions on radiology confirms the diagnosis of an overt myeloma. ${ }^{9}$

CONCLUSION: In any case of refractory cardiac failure with multiple organ involvement, the clinician should have a high index of suspicion of amyloidosis. This case is presented to highlight the association of two separate plasma cell dyscrasias, namely multiple myeloma and primary amyloidosis.

\section{BIBLIOGRAPHY:}

1. Nair MK, Varghese C, Krishnan E, et al. Survival in multiple myeloma in Kerala. Natl Med J India. 1993; 6(1): 7-10.

2. Desport E, Bridoux F, Sirac C, et al. Al amyloidosis. Orphanet J Rare Dis. 2012; 21; 7: 54.

3. Palumbo A, Sezer O, Kyle R, Miguel JS, Orlowski RZ, Moreau P. International Myeloma Working Group guidelines for the management of multiple myeloma patients ineligible for standard high-dose chemotherapy with autologous stem cell transplantation. Leukemia. 2009; 23(10): 1716-30.

4. Kyle R A. Amyloidosis. Circulation 1995; 91: 1269-1271. 
5. Gertz MA, Merlini G. Definition of organ involvement and response to treatment in $\mathrm{AL}$ amyloidosis: an updated consensus opinion. Amyloid2010; 17: 48-49.

6. Dinner S, Witteles W, Witteles R, Lam A, Arai S, Lafayette R, et al.The prognostic value of diagnosing concurrent multiple myeloma in immunoglobulin light chain amyloidosis. $\mathrm{Br} \mathrm{J}$ Haematol. 2013; 161(3): 367-72.

7. Madan S, Angela Dispenzieri, Martha Q. Lacy, Francis Buadi, Suzanne R. Hayman, Steven R. Zeldenrust, Primary amyloidosis in Pre-existing multiple myeloma Mayo Clin Proc.2010; 85(3): 232-238.

8. Dubrey SW, Hawkins PN, Falk RH. Amyloid diseases of the heart: assessment, diagnosis, and referral. Heart 2011; 97: 75e84.

9. Falk RH. AL amyloidosis or multiple myeloma? An important distinction. Br J Haematol. 2014; 164(5): 748-9.

\section{AUTHORS: \\ 1. Parathan K. K. \\ 2. Mahendra Kumar K. \\ 3. Kannan R. \\ 4. Chitrambalam P. \\ 5. Volga $\mathrm{H}$.}

\section{PARTICULARS OF CONTRIBUTORS:}

1. Assistant Professor, Department of General Medicine, Saveetha Medical College and Hospital, Saveetha Nagar, Thandalam, Chennai, Tamilnadu.

2. Assistant Professor, Department of General Medicine, Saveetha Medical College and Hospital, Saveetha Nagar, Thandalam, Chennai, Tamilnadu.

3. Associate Professor, Department of General Medicine, Saveetha Medical College and Hospital, Saveetha Nagar, Thandalam, Chennai, Tamilnadu.

FINANCIAL OR OTHER COMPETING INTERESTS: None
4. Professor, Department of General Medicine, Saveetha Medical College and Hospital, Saveetha Nagar, Thandalam, Chennai, Tamilnadu.

5. Assistant Professor, Department of Pathology, Saveetha Medical College and Hospital, Saveetha Nagar, Thandalam, Chennai, Tamilnadu.

\section{NAME ADDRESS EMAIL ID OF THE CORRESPONDING AUTHOR:}

Dr. Kannan R, Associate Professor, Department of General Medicine, Saveetha Medical College and Hospital, Saveetha Nagar, Thandalam, Chennai-602105, Tamilnadu, India.

E-mail: endork@yahoo.com

Date of Submission: 12/09/2015. Date of Peer Review: 14/09/2015. Date of Acceptance: 29/09/2015. Date of Publishing: 08/10/2015. 